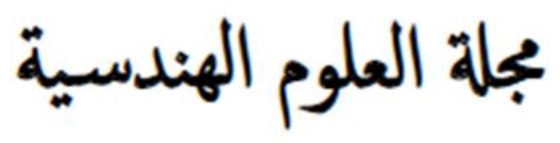

\title{
Effect of Skew Angle on Bridge Superstructures
}

\author{
Abdelhameed H. M. Ali ${ }^{1, *}$ and Anwar Adam Ahmed ${ }^{1}$ \\ 1 Civil Engineering Department, Omdurman Islamic University, Omdurman, Sudan

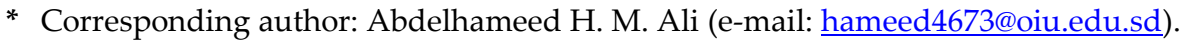

Article history: Received 13 March 2020, Received in revised form 4 November 2020, Accepted 11 November 2020

\begin{abstract}
In this paper, the effect of skew angle on reinforced concrete skew bridge decks is presented by using the grillage analogy. The actual deck system of the bridge is represented by an equivalent grillage of longitudinal and transverse beams. A span $26 \mathrm{~m}$ of simply supported bridge deck is taken as the case study to obtain the values of the bending moment's distribution versus span length for the one type of skewness and the results are compared against the moments of the right deck span of the bridge. The analysis results were based (BS5400) dead and live loads using Structural Analysis program (SAP2000). The analysis provided useful information about the variation of moments and shear forces with respect to change in skewness. It is concluded that in skew bridge deck, the bending moment is decreased, but torsional moments and shear forces are increased by increasing the skew angle. It is noticed that the maximum bending moment at skew angle $55^{\circ}$, by $76 \%$ in comparison with zero skew angle. On the other hand the maximum torsional moment increases for the same skew angle $\left(55^{\circ}\right)$ more than five times than with zero skew angles.
\end{abstract}

Keywords: skew angle, grillage analogy, right, SAP2000, torsional moments and increases.

\section{INTRODUCTION}

Bridge decks are developing as fast as they have at any time since the beginning of the industrial revolution. The diversity of sites is increasingly challenging the ingenuity of engineering to produce new structural forms and appropriate materials. Methods of the analysis have developed equally rapidly, particularly with the use of computer method. The accessibility of microcomputer is making it progressively easier for engineer to Analyze Bridges with complex cross sections and complicated skew, curved and continuous spans. In the past a considerable amount of the theoretical and experimental research was required to develop the design method. Today however several techniques have been developed to such usable form that with an understanding of physical behaviors, the designer can analyze complex decks without recourse to complicated mathematical theory.

The design of skew bridges has special consideration particularly in bridges up to $20 \mathrm{~m}$ span. The skew is defined as the inclination of the abutment to the perpendicular between the free edges.

The effect of skew angle up to $20^{\circ}$ can be neglected on the variation of bendings and shears in slabs and beams. Bridges with skew angles up to $20^{\circ}$ can be analyzed as straight bridges.

Generally, in skew bridges the behavior of the structure near the bearings particularly at the obtuse corner requires special consideration.

The special characteristics of skew of a slab deck are, torsional moments in the deck slab, concentration of reaction forces and negative moments at obtuse corner, low reactions and a possibility of uplift reaction forces at acute corner, bending moments at the edge of concrete slab bridge adjacent to the abutment and in the direction normal to it, distribution of bending moments in cast in situ slabs.

The increasing demand for high skew bridges has been accompanied by the Development of computer aided methods of analysis, and it is now generally possible to analyze and design a structure at any angle of skewness. Many methods are used in analysis of skew bridges such as grillage and finite element methods. 
Generally, grillage analysis is the most common method in bridge analysis. In this method the deck is represented by an equivalent grillage of beams, the finer grillage meshes, provides more accurate results. The method is applicable to bridge decks with simple as well as complex configurations with almost the same ease and confidence.

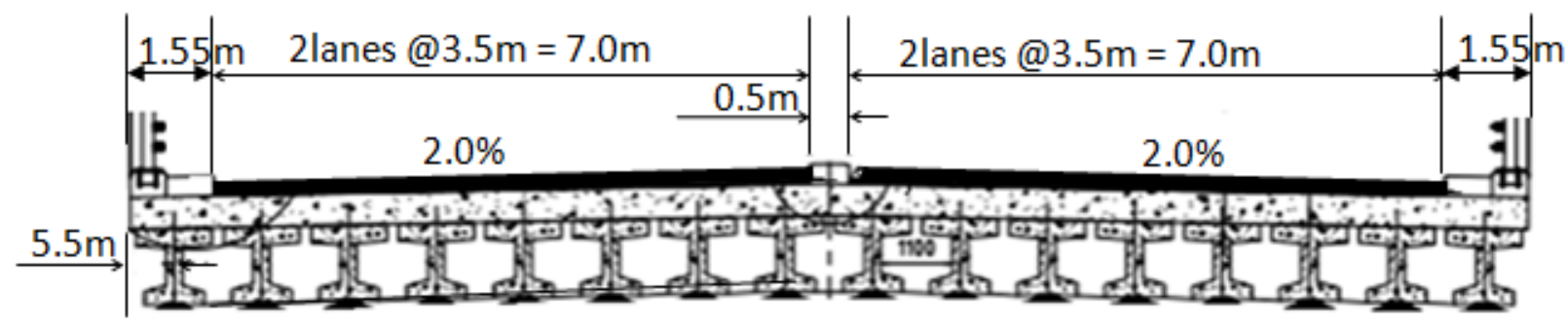

Fig. 1: Precast Prestress Girder

Wad Elbasheer Overpass is the elevated part of the Wad Elbasheer Interchange providing a grade separated junction. The bridge has an overall length of $106 \mathrm{~m}$ between abutment bearings with a $26 \mathrm{~m}$ central spans each side. The bridge carries a dual two lane highway with $7.5 \mathrm{~m}$ carriageways separated by a $0.5 \mathrm{~m}$ wide central reserve. A $0.6 \mathrm{~m}$ wide raised shoulder is provided at the outer edge of each carriageway. The deck comprises precast concrete beams carrying an insitu concrete deck slab. Each span is effectively simply supported but adjacent spans are joined by link slabs to provide a continuous deck as supported on elastomeric bearings and expansion joints are provided at each abutment. The deck is supported on reinforced concrete piers and abutments with conventional pad foundations. These calculations cover the derivation of the loading applied to the substructure by the deck.

In this study the central span has been taken as the case study of this paper is deck of the bridge consisting of deck and beam of simply supported span length $(26 \mathrm{~m})$ center to center of piers, the total width of deck is $(17.6 \mathrm{~m})$, the span of the bridge deck is constructed of the seventeen prestress concrete girders spaced at $0.8 \mathrm{~m}$ which are connected by cast in situ deck slab of thickness $(20 \mathrm{~cm})$ and end diaphragms as shown in Fig.(1). The deck slab is covered by asphalt surfacing layer of $(7 \mathrm{~cm})$, the slab thickness is increased by additional concrete layer to be $(40 \mathrm{~cm})$ for $(2.5 \mathrm{~m})$ width at the two sides of the $(9 \mathrm{~m})$ carriageway.

The grillage analogy is used in the analysis of the bridge deck. This method is based on representing the actual decking system of the bridge by an equivalent grillage of beams. For the purpose of analysis the distributed bending and torsional stiffness of the decking system are assumed to be concentrated in these beams. In this project the computer program (SAP2000) Structural Analysis program was used and the grillage system was used to describe the concrete bridge which consists of seventeen longitudinal girder deck slab and two end diaphragms the bridge has been designed by A\&A for urban development and reviewed by Alaani and Alshama and constructed in Sudan with skew angle of 600 .

the data prepared for the skew of $\left(0^{\circ}, 5^{\circ}, 10^{\circ}, 15^{\circ}\right.$, $20^{\circ}, 25^{\circ}, 30^{\circ}, 35^{\circ}, 40^{\circ}, 45^{\circ}, 50^{\circ}$ and $55^{\circ}$ ) . The span is idealized by substituting it by (442) longitudinal grillage members located along the webs centerlines and (442) transverse grillage members as shown in Fig.(2) The grill age are rigidly connected at the intersection joints and the span is supported at its ends on the line of supports as in Fig.(2) A linear elastic analysis was used. The recommendations suggested by (West, 1973) were used to compute the properties of the grillage members .The required section properties are the flexural inertia (I), the torsional inertia (J), the cross section area (A) of each grillage members, the cross section area is used to include the shearing deformation in deflection calculations. The grillage members were classified into seventeen (L1-L17) types for this span according to the section type. Table(1) shows the grillage member properties, where I and J 
are calculated by using the computer program SAP2000.

TABLE 1: GRILLAGE MEMBER PROPERTIES

\begin{tabular}{|c|c|c|c|}
\hline Member Type & $\mathrm{I}\left(\mathrm{m}^{4}\right)$ & $\mathrm{J}\left(\mathrm{m}^{3}\right)$ & $\mathrm{A}\left(\mathrm{m}^{2}\right)$ \\
\hline Edge Section & $2.4 \times 10^{-3}$ & 0.15 & 0.18 \\
\hline Inner Section & 0.1069 & 0.605 & 0.714 \\
\hline Transverse Section & $6.667 \times 10^{-4}$ & 0.1667 & 0.22 \\
\hline
\end{tabular}

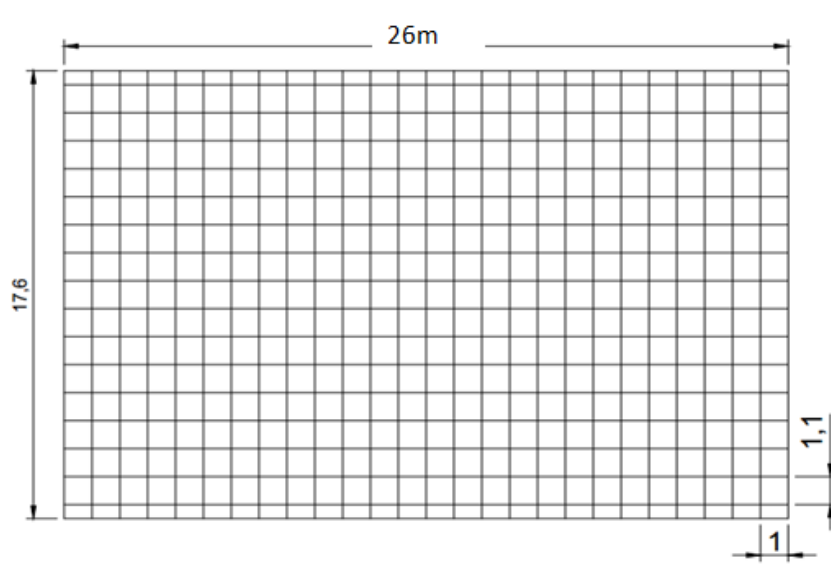

Fig. 2: Bridge Deck Idealization

\section{ANALYSIS AND RESULTS}

This part contains the discussion of analysis results of two girders (Girder one and Girder five) with skew angle up to $55^{\circ}$. The straight girder (with skew angle $0^{\circ}$ )

This type of skew has the most publicity and widespread use in the construction of highway bridges. In this type of skewness, the abutment is rotated at the required angle with keeping the span between the abutments at the same length.

To assess quantitatively the effect of analyzing real life skew bridges, several skew angles $\left(0^{\circ}, 5^{\circ}, 10^{\circ}, 15^{\circ}, 20^{\circ}, 25^{\circ}, 30^{\circ}, 35^{\circ}, 40^{\circ}\right.$, $45^{\circ}, 50^{\circ}$ and $55^{\circ}$ ) are analyzed to find the effect of the skew angle on the maximum moment and maximum torsion. Then the results from the output of analysis of bridge decks are obtained and compared with right bridge to examine the effects on the major principal moments.

The results of bending and torsional moment of girder one and five were presented as shown in Fig. (3 to 10).

The maximum moments have been calculated for this type of skewness under the effect of dead load, live load and total load separately.

Fig.( 3) shows that the relationship between the maximum moments and the skew angles on girder five. It also presents a comparison between the maximum moments obtained under the different types of loadings. The maximum moment under the effect of total load at $0^{\circ}$ Skew angle is $2907 \mathrm{kN}$.m which decreases to $2204 \mathrm{kN} . \mathrm{m}$ at $55^{\circ}$ skew angle, and the maximum moment under the effect of live loads at $0^{\circ}$ skew angle is $1307 \mathrm{kN}$.m which decreases to $972 \mathrm{kN} . \mathrm{m}$ at $55^{\circ}$ skew angle. Also the maximum moment under the effect of dead loads at $0^{\circ}$. Skew angle is $1601 \mathrm{kN}$.m which decreases to $1231 \mathrm{kN} . \mathrm{m}$ at $55^{\circ}$ skew angle.

The relationship between the maximum torsions and the skew angles under the total load effect is shown in Fig.(4). The maximum torque under the effect of total load at $0^{\circ}$ skew angle is $65 \mathrm{kN}$.m which increases to $274.7 \mathrm{kN}$.m at $55^{\circ}$ skew angle.

Fig.(6) shows the decrease percent of bending moment that is located approximately in the edge span, under the effect of total loads. Fig. (7) show the increase percent of torsion. In this figure for different skew angles from 0 o to $55^{\circ}$. Fig.(9) shows the bending moment diagrams for the girder (G1) that is located approximately in the edge span, under the effect of total loads. The relationship between the distance and the average moment in the joints is appearing clearly in this figure for the different skew angles from $0^{\circ}$ to $55^{\circ}$. The value of moment diagrams are decreased with the increasing of the skew angles in all joints except the joints at supports at which the moment approaches to zero (simply supported span). Fig.(9) shows the bending moment diagrams for the girder five which is located in the mid span under the effect of total loads. The relationship between the distance and the average moment in the joints is appearing clearly in this figure for different skew angles from $0^{\circ}$ to $55^{\circ}$.

The values of moment are decreased with increasing the skew angles and Fig.(10) shows the bending moment value for the girder one which is located in the mid span of the girder under the effect of total loads. The relationship between the distance and the average moment in the joints is appearing clearly in this figure for 
different skew angles from $0^{\circ}$ to $55^{\circ}$. The values of moment value are decreased with increasing the skew angles.

\section{CONCLUSIONS}

This paper presents the use of grillage analysis to analyzed concrete bridge.

The grillage analogy of analysis for bridge decks is versatile, easy for engineers to visualize and prepare the data .To assess quantitatively the effect of analyzing real life skew bridges, several skew angles $\left(0^{\circ}, 5^{\circ}, 10^{\circ}\right.$, $15^{\circ}, 20^{\circ}, 25^{\circ}, 30^{\circ}, 35^{\circ}, 40^{\circ}, 45^{\circ}, 50^{\circ}$ and $55^{\circ}$ ) are analyzed to find the effect of the skew angle on the maximum moment and maximum torsional then the results from the output of analysis of bridge decks are obtained and compared with right bridge to examine the effects on the major principal moments. . Based on the results of the analysis, the following conclusions are drawn:-

In this type of skewness the abutment is rotated at the required angle with keeping the span between the abutments at the same length.

This is more widespread in the skew highway bridges, the maximum moment in the longitudinal direction decreases with increases in the skew angle. The maximum moment is reached as $76 \%$ at skew angle $55^{\circ}$.

- On the other hand the maximum torque increases with increases of skew angle for more than five times the torque in the right span at angle $55^{\circ}$.

\section{COMPARISONS OF RESULT}

Abbas, 2002; had been working on structural behavior of simply supported skew bridge, His case study consisted of four longitudinal girders, Deck slabs and two end diaphram. The case study bridge has been designed by Dr. Kwan Alaani and constructed in Yemen with skew angle 35, 1997. The data is prepared for six skew angles (10, $20,30,40,50$ and 60 ). This data consisted of bridge geometry (coordinate and member incidences) member properties (cross section area and moment of inertia), material properties such as density, Poisson's ratio and moduli's of elasticity. Analysis was carried out by applying HA loading according to BS 5400, using structural analysis program STAADIII.
Six skew angles $(10,20,30,40,50$ and 60$)$ were considered for grillage analysis.

The results for six bridge models were summarized as follows:

(i) The bending moments in structural elements of deck decrease as skew angle increases.

(ii) The shear forces increase as skew angle increases.

(1) The maximum bending moment in the external girder for a skew angle of 100 was $650 \mathrm{kN} . \mathrm{m}$, and for a skew angle of 600 was $350 \mathrm{kN} . \mathrm{m}$ and thus the percentage decrease was $46 \%$. In the present case study the moment of skew angle 100 is $2251 \mathrm{kN}$.m and for $55^{\circ}$ was 1949 kN.m with decrease percentage of $13.4 \%$

(2) For internal girder, the maximum bending moment for a skew angle of 100 was $800 \mathrm{kN}$.m and for a skew angle of 600 was $620 \mathrm{kN} . \mathrm{m}$ and thus the percentage decrease is $22.5 \%$. In the present case study the moment of skew angle 100 was 2871 kN.m and for $55^{\circ}$ was 2204 kN.m with decrease percentage of $23.2 \%$

(3) the difference in decrease percentage in the maximum longitudinal moment of the external and internal girders of Abbas, 2002 case study and present case study resulted from the difference the number of girder bridges.

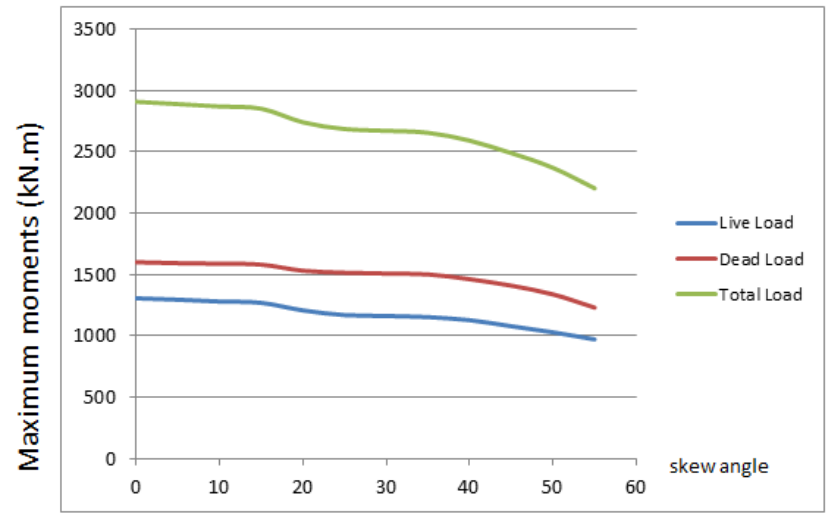

Fig. 3: Relationship between maximum bending moment and skew angle in Girder (G5)

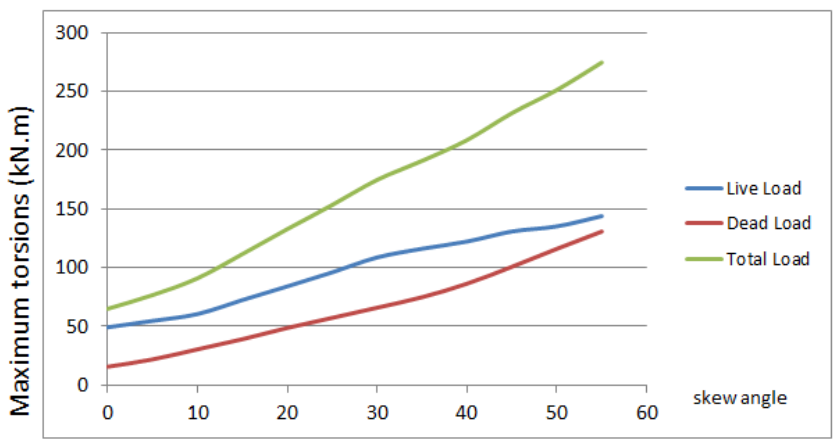

Fig. 4: Relationship between maximum torsional moment and skew angle in Girder (G5) 


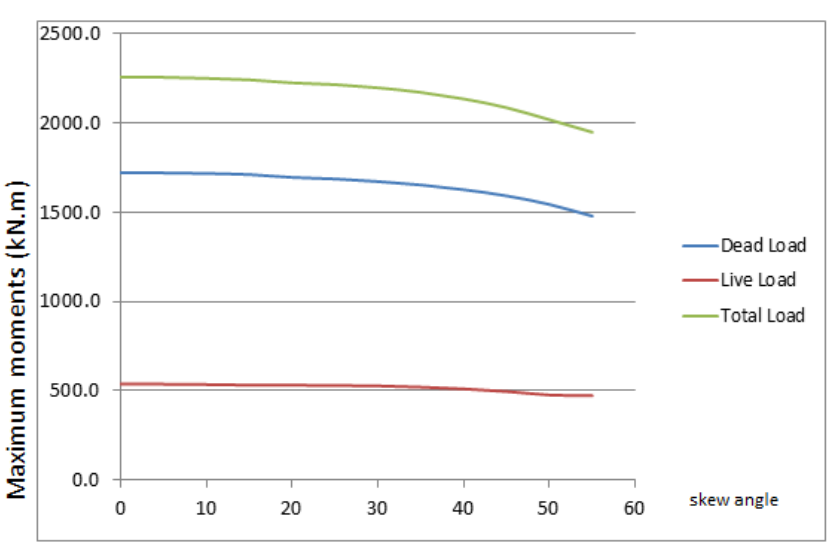

Fig. 5: Relationship between maximum bending moments and skew angle in Girder (G1)

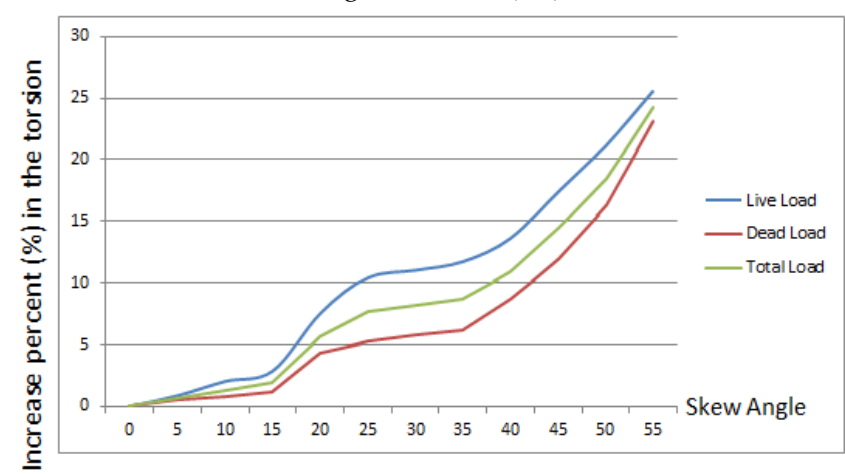

Fig. 6: Percentage Increase in the torsional moment in Girder (G5)

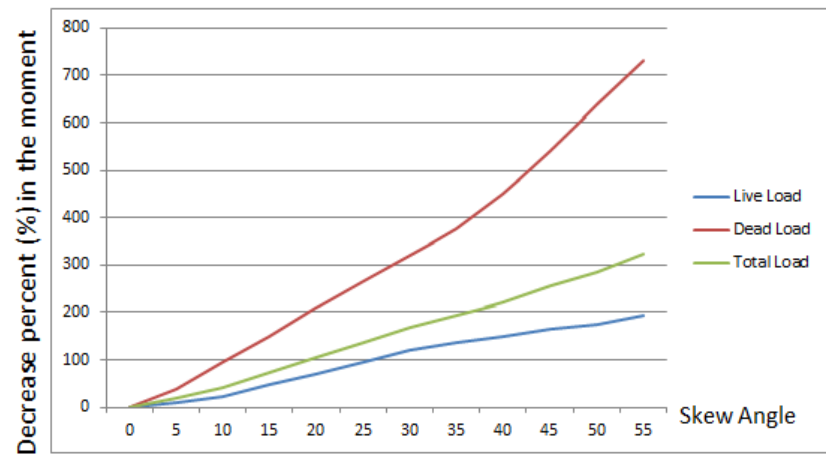

Fig. 7: Percentage Decrease in the bending moments in Girder (G5)

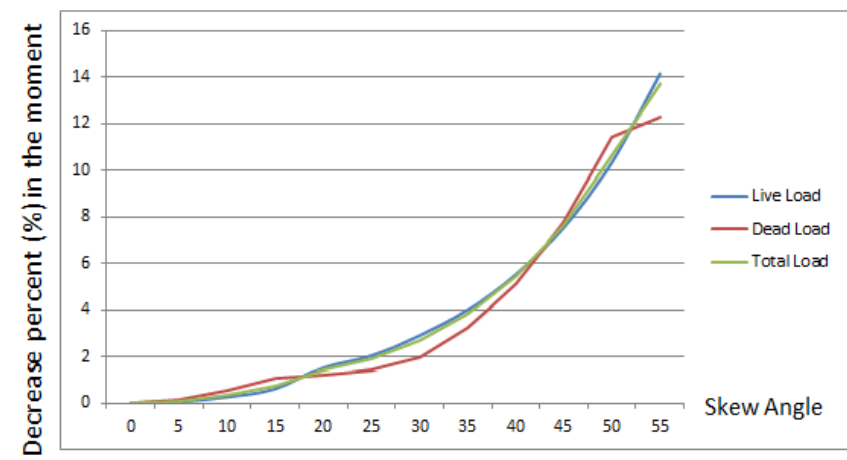

Fig. 8: Percentage Decrease in the bending moments in Girder (G1)

\section{RECOMMENDATIONS}

During the work, a number of issues regarding the grillage analogy of bridge decks has been identified. The most important will be listed here as base for future research.
1. In this project theoretical study only has been carried out, but anyone interested in skew bridges can do experimental work on bridge models to verify the theoretical results.

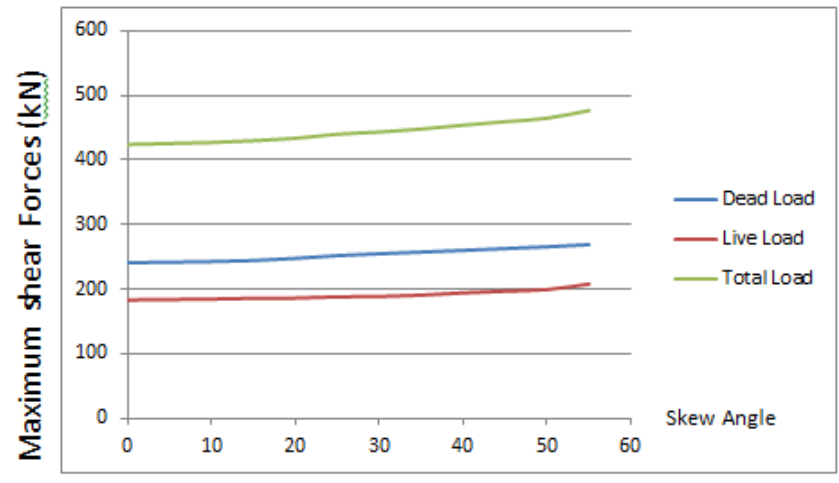

Fig. 9: Variation of Shear Forces in Girder (G5)

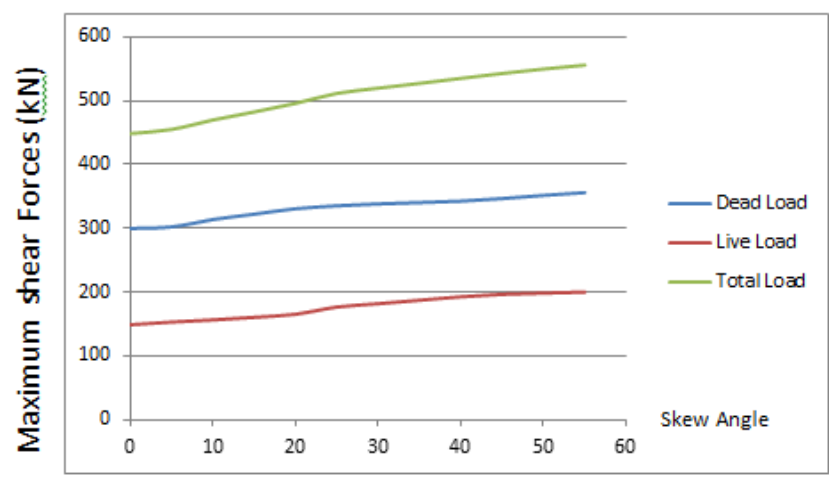

Fig. 10: Variation of Shear Forces in Girder (G1)

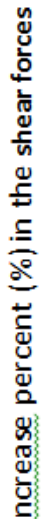

Fig. 11: Percentage Increase in the Shear Forces in Girder (G5)
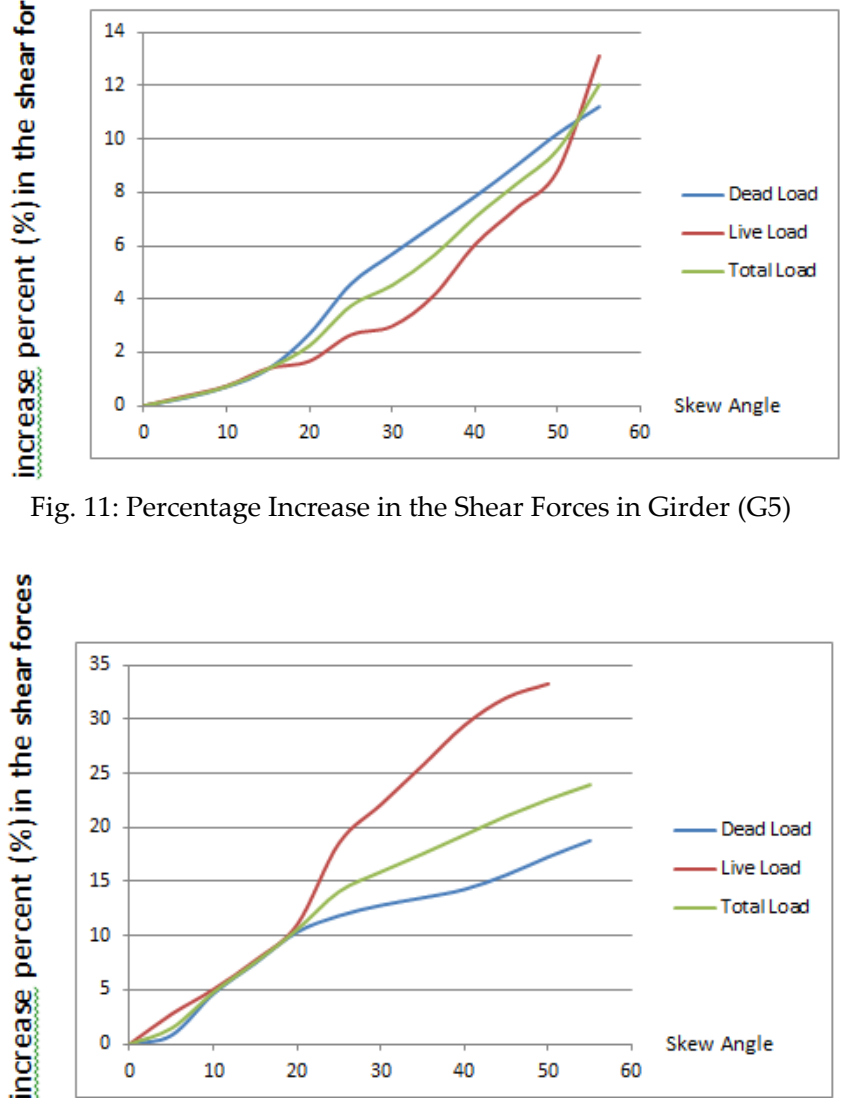

Fig. 12: Percentage Increase in the Shear Forces in Girder (G1) 


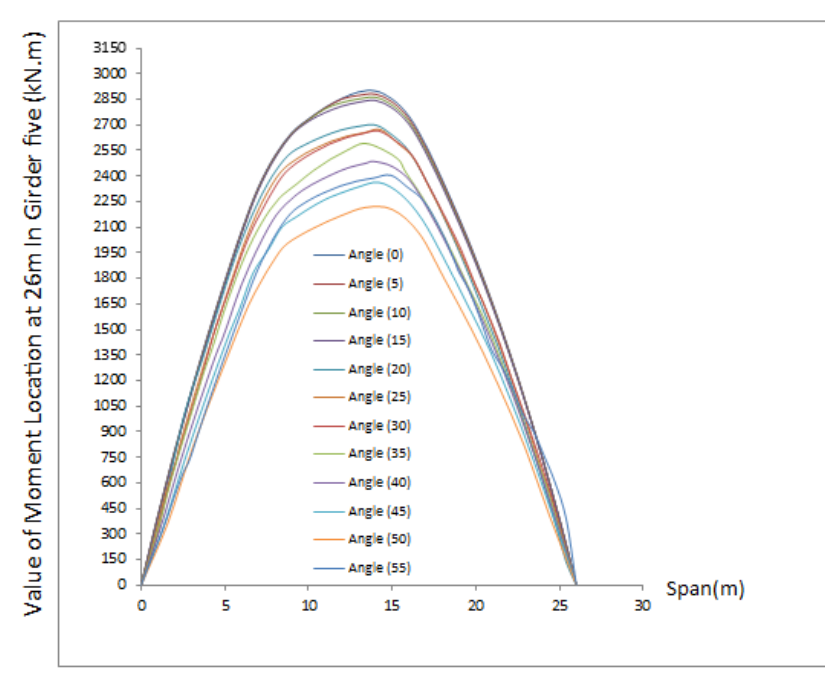

Fig. 13: Variation of bending moments along the span at Girder (G5)

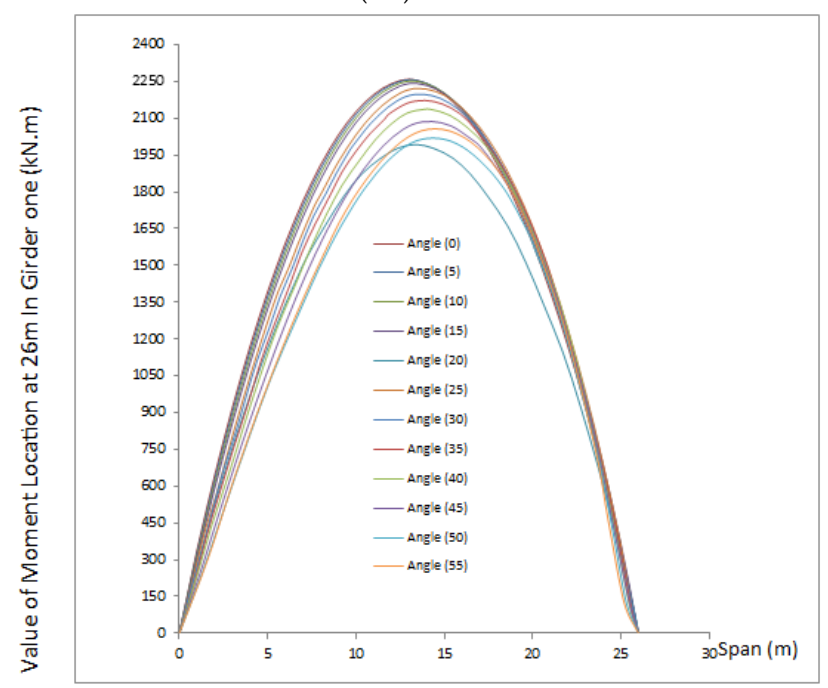

Fig. 14: Variation of bending moments along the span at Girder (G1)

2. It is also recommended that for skew angle less than 200, it is better to design the skew bridge as right bridges. It is also not beneficial to study the skew bridge which has skew angle greater than $55^{\circ}$, because if the skew angle is greater than $55^{\circ}$, the results of skew angle $55^{\circ}$ are sufficient to be used.

3. In the case study considered in this project, the type of deck is slab-beam Bridge. Other types of decks such as slab decks, box-sections decks, etc. may be recommended for study.

4. The case study was simply supported skew bridge, but it is recommended to extend this research to cover other types of bridges such as continuous bridges and rigid frame bridges.

5 . The case study under consideration is concrete bridge, but this can be extended to cover other bridge materials such as steel.
6. It is finally noted that this investigation was mainly concerned with the evaluation of the bending moments and torsional moment designs; the evaluation of defection is a vital necessity. Thus it is recommended that for further work, this must be included.

\section{REFERENCES}

[1] Bakht, B., October 1988,"Analysis of Some Skew Bridges as Right Bridges", Journal of Structural Engineering, ASCE, Vol. 114, No. 10, 2307-2322.J. U. Duncombe, "Infrared navigation-Part I: An assessment of feasibility," IEEE Trans. Electron Devices, vol. ED-11, pp. 34-39, Jan. 1959.

[2] Gupta, T., and Misra, A., February 2007," Effect on Support Reactions of TBeam Skew Bridge Decks", ARPN Journal of Engineering and Applied Sciences,Vol. 2, No. 1.

[3] Hambly, E. C.,1976, "Bridge Deck Behaviour", Chapman and Hall, London.

[4] Kakish, M., 2007,"Bending Moments Distribution at the Main Structural Elements of Skew Deck-Slab and Their Implementation on Cost Effectiveness", American Journal of Applied Sciences, Vol. 4, Issue 12, 1036-1039.

[5] West, R., 1973," Recommendations on the Use of Grillage Analysis for Slabs and Pseudo-Slab Bridge Decks", Cement and Concrete Association.

[6] EC7 (1994) Euro code 7: "Geotechnical Design, Part 1: General Rules, European pre standard ENV1997-1:1994", European Committee for Standardization, Brussels.

[7] Keogh, D.L. and O'Brien, E.J. (1996), " Recommendations on the use of a 3-D grillage model for bridge deck analysis, Struct. Eng. Rev., 8(4), 357-66.

[8] Lee, D.J. (1994), " Bridge Bearings and Expansion Joints, 2nd edn, E\&FN Spon, London.

[9] West, R. (1973) C\&CA/CIRIA , "Recommendations on the Use of Grillage Analysis for Slab and Pseudo-slab Bridge Decks", Cement and Concrete Association, London.

[10] Sukhen Chatterjee, 2003, " the Design of Modern Steel Bridge", Osney- Oxford, Second Edition.

[11] Zienkiewicz, O.C. and Cheung, Y.K. (1964), "The Finite Element Method for Analysis of Elastic Isotropic and Orthotropic Slabs", Proc. Inst. Civil Eng., 28, 471-88.

[12] Richard M. Barker, 2007 , "Design of High Way Bridge" , Second edition New Jersey, London.

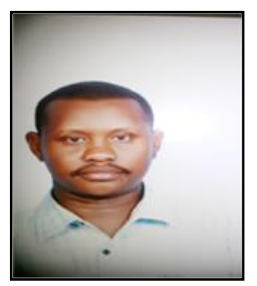

Abdelhameed Hamed Mohammed Ali received his bachelor of science degree in Civil engineering from Omdurman Islamic University, Sudan in 2005; the master of science in Civil engineering (Structures) from Karary University, Sudan in 2012 and Ph.D of science in Civil engineering (Structures) from Karary University, Sudan in 2016. He has been appointed as a lecturer at Omdurman Islamic University, Khartoum, Sudan since 2006.

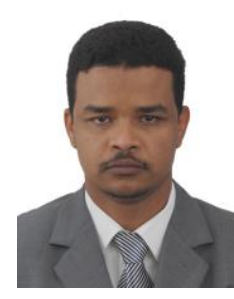

Anwar Adam Ahmed received his bachelor of science degree in Civil engineering from Omdurman Islamic University, Sudan in 2006; the master of science in Civil engineering (Structures) from Karary University, Sudan in 2012. He has been appointed as a lecturer at Omdurman Islamic University, Khartoum, Sudan since 2008 . 